\title{
In situ constructive myocardial remodeling of extracellular matrix patch enhanced with controlled growth factor release
}

\author{
Akiko Tanaka, MD, PhD, ${ }^{a}$ Keigo Kawaji, $\mathrm{PhD},{ }^{\mathrm{b}}$ Amit R. Patel, MD, ${ }^{\mathrm{b}}$ \\ Yasuhiko Tabata, PhD, DMedSci, DPharm, ${ }^{\mathrm{c}}$ Martin C. Burke, DO, ${ }^{\mathrm{b}}$ Mahesh P. Gupta, PhD, ${ }^{\mathrm{a}}$ and \\ Takeyoshi Ota, MD, $\mathrm{PhD}^{\mathrm{a}}$
}

\begin{abstract}
Objective: In an effort to expand treatment for advanced heart failure, we sought to develop a tissue-engineered cardiac patch for constructive and functional in situ myocardial regeneration.
\end{abstract}

Methods: An extracellular matrix patch derived from porcine small intestine sub-
mucosa was incorporated with a controlled release of basic fibroblast growth factor.
The patch was surgically implanted into the porcine right ventricle (group B, $\mathrm{n}=5$ ).
Untreated extracellular matrix (group $\mathrm{U}$ ) and Dacron (group $\mathrm{D}$ ) patches served as
control ( $\mathrm{n}=5$ /group). Cardiovascular magnetic resonance was performed in all 3
groups 60 days postsurgery to evaluate regional contractility with peak longitudinal
strain, perfusion with relative maximum upslope, and extent of fibrosis/edema with
extracellular volume fraction. Electrophysiologic-anatomic mapping was per-
formed in group B. Histology and quantitative reverse transcription-polymerase
chain reaction were performed for further tissue characterization.

Results: Cardiovascular magnetic resonance-derived parameters were significantly better in group $\mathrm{B}$ compared with groups $\mathrm{U}$ and $\mathrm{D}$ (strain: group $\mathrm{B}=-16.6 \%$ $\pm 1.8 \%$, group $\mathrm{U}=-14.7 \% \pm 1.2 \%$, group $\mathrm{D}=-9.0 \% \pm 1.5 \%, P<.001$; upslope: group $\mathrm{B}=13.7 \% \pm 1.1 \%$, group $\mathrm{U}=10.8 \% \pm 1.3 \%$, group $\mathrm{D}=6.4 \% \pm 1.8 \%, P<.001$; extracellular volume: group $\mathrm{B}=45 \% \pm 7 \%$, group $\mathrm{U}=54 \% \pm 10 \%$, group $\mathrm{D}=70 \% \pm 10 \%, P=.003)$. Histology in group $\mathrm{B}$ showed a homogenous distribution of host cells, including tropomyosin and $\alpha$-sarcomeric actinin-positive maturing cardiomyocytes. Group B demonstrated the greatest degree of vasculogenesis as determined by capillary density analysis (group $\mathrm{B}=19.5 \pm 6.2 / \mathrm{mm}^{3}$, group $\mathrm{U}=12.7 \pm 2.5 / \mathrm{mm}^{3}$, group $\mathrm{D}=6.9 \pm 3.7 / \mathrm{mm}^{3}$, $P<.001)$. Quantitative reverse transcription-polymerase chain reaction supported the histologic findings. Electrophysiologic-anatomic mapping in group B indicated positive electrical conductivity in the patch area.

Conclusions: The extracellular matrix patch enhanced with controlled release of fibroblast growth factor facilitated in situ constructive repopulation of the host cells, including cardiomyocyte and functional regeneration, increased regional contractility and tissue perfusion, and positive electrical activity in a porcine preparation. (J Thorac Cardiovasc Surg 2015;150:1280-90)

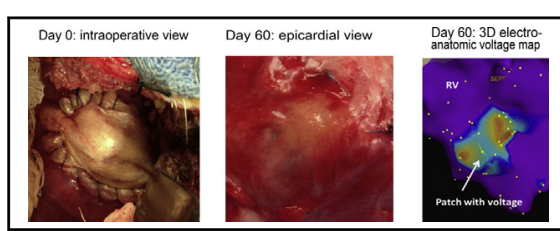

The ECM patch enhanced with controlled release of growth factor.

\section{Central Message}

The ECM patch enhanced with controlled release of growth factor may expedite in situ constructive myocardial regeneration.

\section{Perspective}

The ECM patch enhanced with controlled growth factor release has great potential to facilitate constructive myocardial regeneration. Further evaluation is warranted.

See Editorial Commentary page 1290.

See Editorial page 1035 .
From the Departments of a Surgery and ${ }^{b}$ Medicine, The University of Chicago, Chicago, Ill; and ${ }^{\mathrm{c}}$ Department of Biomaterials, Field of Tissue Engineering, Institute for Frontier Medical Sciences, Kyoto University, Kyoto, Japan.

This study was supported by the American Heart Association Scientist Development Grant (Principal Investigator TO, 11SDG5120010), the National Center for Advancing Translational Sciences of the National Institutes of Health (Principal Investigator TO UL1 TR000430), and Institute of Translational Medicine Pilot Award (Principal Investigator KK CTSA UL1 TR000430).
Received for publication June 3, 2015; revisions received July 20, 2015; accepted for publication July 22, 2015; available ahead of print Sept 3, 2015.

Address for reprints: Takeyoshi Ota, MD, PhD, Department of Surgery, Center for Aortic Diseases, Section of Cardiac and Thoracic Surgery, The University of Chicago, 5841 S. Maryland Ave, MC5040, Chicago, IL 60637 (E-mail: tota@ surgery. bsd.uchicago.edu).

$0022-5223 / \$ 36.00$

Copyright () 2015 by The American Association for Thoracic Surgery

http://dx.doi.org/10.1016/j.jtcvs.2015.07.073 


\section{Abbreviations and Acronyms \\ $\mathrm{CMR}=$ cardiovascular magnetic resonance \\ $\mathrm{ECM}=$ extracellular matrix \\ $\mathrm{ECV}=$ extracellular volume fraction \\ FGF-2 = basic fibroblast growth factor \\ LGE = late gadolinium enhancement \\ MOLLI = modified Look-Locker inversion recovery \\ ROI = region-of-interest \\ SENC = strain encoding \\ SIS-ECM $=$ extracellular matrix derived from porcine small intestine submucosa \\ SVR = surgical ventricular restoration \\ $\mathrm{vWF} \quad=$ von Willebrand factor}

Supplemental material is available online.

Symptomatic heart failure is a major health issue with poor prognosis and limited quality of life. ${ }^{1}$ Heart transplantation and mechanical circulatory support are the gold standard strategies to treat refractory end-stage heart failure. However, not all patients with advanced heart failure benefit from these treatment options because of donor shortages or strict criteria for surgical indications, such as age. In an effort to develop an alternative therapy for patients with endstage heart failure, we have sought to develop a tissueengineered cardiac patch that constructively remodels with in situ functional myocardial regeneration.

Decellularized extracellular matrix (ECM) materials have served as a mechanical framework to repair and replace human tissues. ${ }^{2}$ They cause minimal immunologic response and allow site-specific host cell repopulation, possibly by auto-seeding of host progenitor cells from the bloodstream. ${ }^{3}$ ECM derived from porcine small intestine submucosa (SIS) has been clinically adapted to repair pericardial or atrial septal defect with excellent results, ${ }^{4}$ and its application recently has been extended to heart valve reconstructions. ${ }^{5}$ Histologic studies have demonstrated that an explanted SIS-ECM used for pericardium reconstruction was remodeled with connective tissue similar to the native pericardium $^{4}$ and that SIS-ECM implanted as a cardiac valve was covered with neointima in 17 days. ${ }^{6}$ Toeg and colleagues $^{7}$ reported that the injectable form of SIS-ECM improved left ventricular ejection fraction in a mouse myocardial infarction model. Myocardial injection of SISECM with or without circulating angiogenic cells resulted in better preservation and improvement of cardiac function and partially restored myocardial viability. ${ }^{7}$ These findings suggest that SIS-ECM could be a promising material for site-specific functional remodeling, including myocardium.
A sufficient supply of nutrients and oxygen is indispensable for survival of cells that regenerate in the ECM scaffold and for these cells to maintain their biological functions. ${ }^{8}$ Basic fibroblast growth factor (FGF-2) promotes angiogenesis/vasculogenesis and host cell repopulation, ${ }^{8}$ prevents maladaptive fibrosis, ${ }^{9}$ and is an antiapoptotic factor for endothelial and smooth muscle cells. ${ }^{8}$ Ota and colleagues ${ }^{10}$ reported an application of a unique protein combining a growth factor and a collagen-binding domain for in situ myocardial regeneration. The unique protein provided an anchoring effect to the growth factor in an ECM scaffold and allowed the prolonged presence of the growth factor to expedite myocardial regeneration in the ECM scaffold. ${ }^{10}$ Tabata and Ikada $^{11}$ developed a controlled drug-delivery mechanism using gelatin hydrogel. The gelatin hydrogel binds to FGF-2, preserves its biological properties, and releases it in a sustained manner for up to 5 weeks.

We have developed a novel SIS-ECM cardiac patch enhanced with controlled release of FGF-2. We hypothesized that our tissue-engineered cardiac patch would promote in situ constructive myocardial remodeling and facilitate functional regeneration. We evaluated an implanted SIS-ECM cardiac patch with a comprehensive approach using multiple imaging modalities, including cardiovascular magnetic resonance (CMR), electrophysiologic-anatomic mapping, and histology.

\section{MATERIALS AND METHODS \\ Preparation of Gelatin Hydrogel Sheet}

Gelatin was isolated using an alkaline process from bovine bone with an isoelectric point of 4.9 and a molecular mass of 99,000 kDa (Nitta Gelatin Co, Osaka, Japan). ${ }^{11}$ The gelatin sheets were prepared by chemical crosslinking of a $5 \%$ bovine bone gelatin solution with glutaraldehyde. The sheets were immersed in $50 \mathrm{mmol} / \mathrm{L}$ glycine aqueous solution at $37^{\circ} \mathrm{C}$ for 1 hour to block the residual aldehyde groups of glutaraldehyde. The gelatin sheets were then freeze-dried and sterilized by ethylene oxide gas.

\section{Cardiac Patch Preparation}

SIS-ECM is a collagen construct derived from porcine small intestine (CorMatrix Cardiovascular Inc, Roswell, Ga). A SIS-ECM patch was soaked in natural saline for 30 minutes at room temperature before implantation. For group B, an FGF-2-incorporated gelatin hydrogel sheet was prepared with aqueous FGF-2 (Invitrogen Co, Carlsbad, Calif) with the concentration of $250 \mu \mathrm{g} / \mathrm{mL}$ by impregnation for 30 minutes at room temperature. Then the hydrogel was embedded in the SIS-ECM sheet. For group D, a sterilized Dacron patch was used (Edwards Lifesciences, Irvine, Calif).

\section{Myocardial Repair in a Porcine Model}

The study protocol was approved by the Institutional Animal Care and Use Committee of the University of Chicago. All animals received humane care in compliance with the Guide for the Care and Use of Laboratory Animals, published by the National Institutes of Health (1996).

A female pig, mixed breed of Yorkshire and Landrace $(20-30 \mathrm{~kg}$; $\mathrm{n}=15$ ), was anesthetized, and the heart was exposed via a right anterolateral thoracotomy. A tangential clamp was placed on the right ventricle free wall. The wall was incised in full thickness and substituted with a $30-\mathrm{mm}$ patch with a continuous 5-0 polypropylene suture. SIS-ECM patches with 
FGF-2-impregnated gelatin hydrogel sheet (group B) were implanted in 5 pigs. Likewise, untreated plain SIS-ECM patches (group $\mathrm{U}, \mathrm{n}=5$ ) and Dacron patches (group $D, n=5$ ) were implanted. At 60 days after implantation, the animals were subjected to CMR imaging and electromechanical mapping (group B), and were euthanized for further tissue examinations.

\section{Cardiac Magnetic Resonance Imaging}

CMR assessment was performed for the evaluation of regional myocardial function and physio-mechanical characterization on 1.5-Tesla MRI hardware (Philips Healthcare, Best, The Netherlands) with a 5-channel cardiac array.

\section{Acquisition}

The following 4 sequences were acquired in the short-axis view covering the entire right ventricle under respirator-controlled breathholding strain encoding (SENC), ${ }^{12}$ first-pass myocardial perfusion, ${ }^{13}$ pre- and postcontrast myocardial T1 mapping using the modified LookLocker inversion recovery (MOLLI) ${ }^{14}$ and late gadolinium enhancement (LGE). For all scans, standard CMR parameters were used: field of view $=300$ to $340 \mathrm{~mm}^{2} \times 300$ to $340 \mathrm{~mm}^{2}$; slice thickness $=6$ to $10 \mathrm{~mm}$. Additional CMR parameters, including the pulse sequence flipangles, acquisition scheme and window sizes, and repetition/echocardiography time values were all set to their respective defaults provided on the scanner hardware. Contrast injection was performed using $0.1 \mathrm{mmol} / \mathrm{kg}$ (half dose) of gadobenate dimeglumine (Multihance; Bracco Diagnostic Inc, Princeton, NJ) during first-pass perfusion, where 6 short-axis slices were acquired over every $2 \mathrm{R}-\mathrm{R}$ electrocardiography-gated intervals. A 5( 3 seconds)-3 MOLLI scheme was used for pre- and postcontrast T1 mapping, with the post-MOLLI acquired 8 minutes after contrast injection. LGE imaging using a T1-weighted gradient echocardiography pulse sequence with a phase-sensitive inversion recovery reconstruction was performed 12 to 15 minutes postinjection.

\section{Cardiac Magnetic Resonance Analysis}

First, the LGE images were used to manually verify the location of the right ventricular patch. All subsequent analysis was performed using the identified patch region, and the reference value was obtained from the remote normal myocardium $(\mathrm{n}=15)$.

1) SENC: Longitudinal shortening strain was analyzed with a commercial software (Diagnosoft VIRTUE, Diagnosoft Inc, Morrisville, NC) to determine regional contractility using a region-of-interest (ROI) analysis that accounted for local motion through the cardiac cycle. ${ }^{15}$ The maximal systolic strain was manually chosen from the time frame that exhibited peak deformation at end systole. The time frame from end diastole to end systole was also obtained.

2) Rest perfusion: Signal intensity curve analysis was performed to determine myocardial perfusion on the standard clinical workstation (Philips Healthcare). The maximum upslope of contrast enhancement was obtained from the signal intensity time course of the patch ROI and normalized to the maximum upslope of an ROI placed in the left ventricular cavity to evaluate the regional microvascular tissue perfusion. ${ }^{16}$

3) MOLLI T1 mapping: By using custom software written in MATLAB (The MathWorks, Natick, Mass), pre- and postcontrast T1 map analyses were performed, and the extracellular volume fraction (ECV) of a target ROI was then calculated for fibrous tissue assessment. ${ }^{17}$ The ECV fraction calculation was performed by using ROIs of the target tissue region and myocardial blood by the following equation: $\mathrm{ECV}(\%)=\left([1-\right.$ hematocrit $] \times \Delta \mathrm{R} 1_{\text {target region }} / \Delta \mathrm{R} 1_{\text {blood }}, \Delta \mathrm{R} 1=[$ preGd R1 ROI] $-\left[\right.$ post-Gd R1 ROI]). ${ }^{17}$

\section{Electrophysiologic-Anatomic Mapping}

The subject under anesthesia was prepped with cutaneous mapping electrodes attached to the Velocity Ensite mapping system (St Jude
Medical, Inc, St Paul, Minn). A 7 F quadrapolar 4-mm tip ablation catheter (St Jude Medical, Inc) was advanced into the right ventricle via the right internal jugular vein. The catheter was maneuvered throughout the swine endocardium taking points to triangulate electrical activity and create a point-by-point voltage map within the cardiac chamber.

\section{Histology and Immunohistochemistry}

Excised tissues were fixed in $10 \%$ formalin for paraffin processing or frozen and cut into 5- $\mu \mathrm{m}$ sections. The paraffin sections were deparaffinized and stained with hematoxylin-eosin and Masson-trichrome or prepared for immunohistochemical staining. Monoclonal antibodies specific for von Willebrand factor (vWF) (Dako, Carpinteria, Calif), tropomyosin (Santa Cruz Biotechnology, Inc, Dallas, Tex), and $\alpha$-sarcomeric actinin (Sigma, St Louis, Mo) were used.

\section{Capillary Density}

The vWF-positive capillaries were counted under the $200 \times$ microscopy. Twenty fields were randomly selected in each patch. Capillary density was expressed as the mean number of vessels per square millimeter. ${ }^{10}$

\section{Quantitative Reverse Transcription-Polymerase \\ Chain Reaction}

Quantitative reverse transcription-polymerase chain reaction was performed to quantify the expression of a variety of gene transcripts to have greater insight into the relative presence of various cell types and growth factor expression in the patches at 60 days after implantation $(n=5$ for each group), using the PrimeTime quantitative reverse transcriptionpolymerase chain reaction assays probe (Integrated DNA Technologies, Inc, Coralville, Iowa) and DNA Engine Opticon2 (Bio-Rad Laboratories, Hercules, Calif), as previously described. ${ }^{10}$ The tissues were taken from the center of the patches and stored in an RNA stabilization reagent (RNAlater, Qiagen, Valencia, Calif). Transcripts that were analyzed included smooth muscle $22 \alpha$, vimentin, $\beta$-myosin heavy chain, vWF, FGF-2, and vascular endothelial growth factor. Results were normalized to the level of porcine glyceraldehyde 3-phosphate dehydrogenase transcripts. The sequences of the specific primers and probes are shown in Table E1.

\section{Statistical Analysis}

Data were tested for normality and expressed as mean \pm standard deviation or median and range after the Shapiro-Wilk test result. The statistical differences in all data were determined by the Student $t$ test or Wilcoxon rank-sum test between groups using JMP (SAS Institute, Inc, Cary, NC).

\section{RESULTS}

All 15 pigs survived the surgery, and CMR imaging was successfully performed 60 days after the surgical patch implantation.

\section{Cardiovascular Magnetic Resonance}

Strain for regional contractility (strain encoding). Longitudinal strain in the area of the patch was as follows (Figure 1, A): group $\mathrm{B}=-16.6 \% \pm 1.8 \%$, group $\mathrm{U}=-14.7 \% \pm 1.2 \%$, group $\mathrm{D}=-9.0 \% \pm 1.5 \%$, and normal ventricle $=-22.1 \% \pm 2.3 \%$. There were significant differences between group $\mathrm{B}$ and group $\mathrm{D}(P<.001)$, and group $\mathrm{U}$ and group $\mathrm{D}(P<.001)$. Group $\mathrm{B}$ had numerically but nonstatistically greater strain value than group $\mathrm{U}$ $(P=.087)$. The time to peak longitudinal strain (Figure 1, $B$ ) was significantly delayed in group D compared with the 

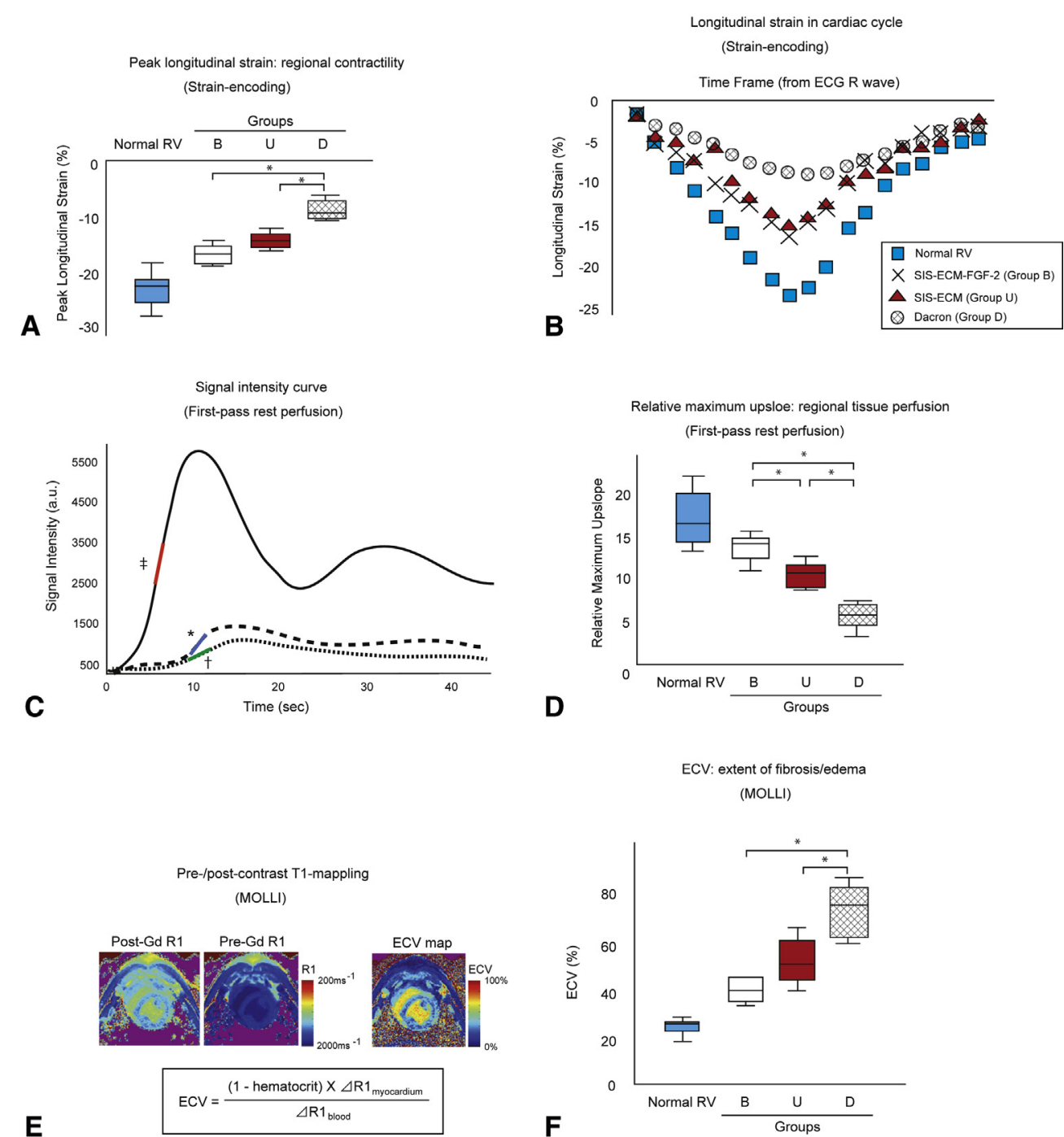

FIGURE 1. CMR imaging. A, Peak longitudinal strain: The highest value in SIS-ECM-FGF-2 demonstrates significantly increased contractility compared with both SIS-ECM and Dacron patch groups. B, Mean longitudinal strain from end diastole to end systole: The peak of the Dacron patch was significantly delayed compared with the normal right ventricle, SIS-ECM-FGF-2, and SIS-ECM, implying passive "akinetic" movement of the patch area in conjunction with surrounding normal right ventricular contractility. C, Representative case of signal intensity curve: Relative maximum upslope (*normal right ventricle, $\dagger$ SIS-ECM-FGF-2) is calculated from the ration of maximum upslope of the target tissue to that of the left ventricular cavity ( $\ddagger)$. D, Relative maximum upslope: The results indicate SIS-ECM-FGF-2 and SIS-ECM gained tissue perfusion. E, Representative figure of T1 maps generated from MOLLI images acquired before and after administration of a gadolinium contrast agent, and the reciprocal of each pixel value is taken to generate R1 maps. The ECV is calculated from the equation as described. F, ECM volume fractions. The results indicate that the patch area was remodeled with more viable tissue in the SIS-ECM-FGF-2 group compared with the SIS-ECM group, and the Dacron group mostly consisted of fibrous/edematous tissue. Group B, SIS-ECM-FGF2. Group U, untreated SIS-ECM. Group D, Dacron patch. Normal $R V$, Self-control normal right ventricle. $R V$, Right ventricle; $E C G$, electrocardiogram; $S I S-E C M-F G F$-2, small intestine submucosa-extracellular matrix-basic fibroblast growth factor; SIS-ECM, small intestine submucosa-extracellular matrix; $a . u$, arbitrary units; $M O L L I$, modified Look-Locker inversion recovery; $G d$, gadolinium; $E C V$, extracellular volume fraction.

other 3 groups (group B: $8.9 \pm 0.7$, group U: $8.9 \pm 1.0$, group D: $9.7 \pm 1.1$, normal ventricle: $8.8 \pm 0.8$, unit: time frame, $P<.05)$, whereas no significant difference was found among group $\mathrm{B}, \mathrm{U}$, and normal ventricle $(P>.2$ in all). The results suggested that groups $\mathrm{B}$ and $\mathrm{U}$ demonstrated regional selfcontractility in the patch areas, whereas there was only passive, akinetic movement of the patch area in group $\mathrm{D}$.
Relative maximum upslope for regional tissue perfusion (signal intensity curve). Relative maximum upslope was obtained from signal intensity curve analysis (Figure 1, $C)$. It was the highest in group $\mathrm{B}$ compared with group $\mathrm{U}$ and $\mathrm{D}$ (group $\mathrm{B}=13.9 \pm 1.2$, group $\mathrm{U}=10.8 \pm 1.3$, group $\mathrm{D}=6.4 \pm 1.8, P<.001$; group $\mathrm{B}$ vs group $\mathrm{D}, P<.001$; group $\mathrm{B}$ vs group $\mathrm{U}, P=.006$ ) (Figure $1, D$ ). The value 


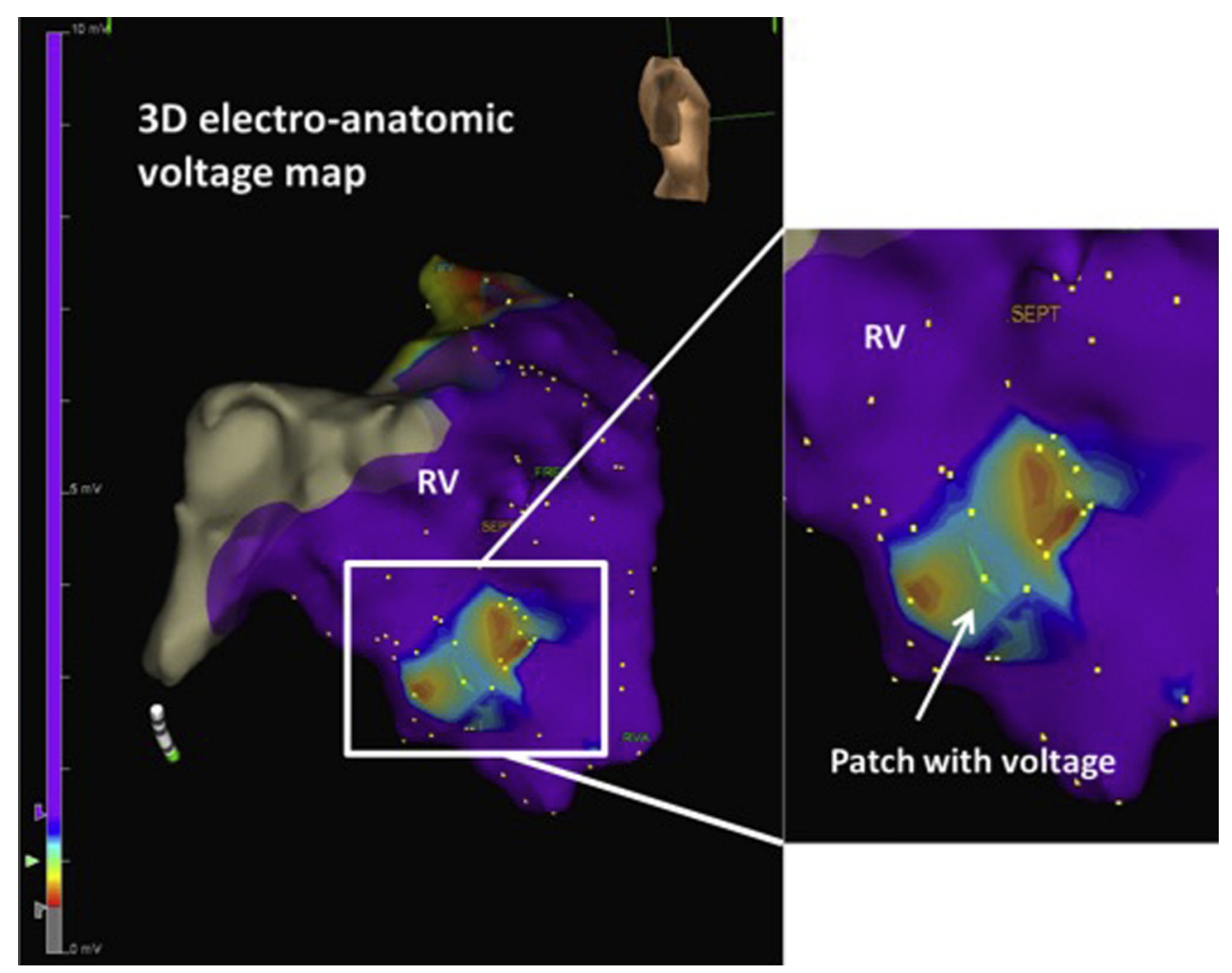

FIGURE 2. Electrophysiologic-anatomic mapping. This represents a right ventricular endocardial voltage map. Purple signifies normal voltage with values greater than $1.5 \mathrm{mV}$. The spectrum of colors (dark blue, light blue, and red) in the patch (inset) reveal a range in voltage from 0.5 to $1.5 \mathrm{mV}$ compared with the surrounding native tissue of $7.01 \mathrm{mV}$. Voltage less than $0.5 \mathrm{mV}$ is gray. $R V$, Right ventricle; $3 D$, 3-dimensional.

in group $\mathrm{U}$ was also significantly greater than in group D. The results implicate that greater intensity of perfusion was present in group B compared with groups $\mathrm{U}$ and D.

Extracellular volume fraction for fibrous and edematous tissue (modified look-locker inversion recovery $\mathrm{T} 1$ mapping). ECV in group B was less than in groups $\mathrm{U}$ and D (Figure 1, E) (group B $=44.8 \% \pm 7.0 \%$, group $\mathrm{U}=54.0 \% \pm 9.6 \%$, group $\mathrm{D}=70.4 \% \pm 10.5 \%$, normal ventricle: $25.5 \% \pm 3.5 \%$; group $\mathrm{B}$ vs group $\mathrm{D}, P=.003$; group $\mathrm{B}$ vs group $\mathrm{U}, P=.126$; group $\mathrm{U}$ vs group $\mathrm{D}$, $P=.033$ ) (Figure $1, F$ ). These findings imply that the patch area was remodeled with more viable tissue in group B compared with groups $\mathrm{U}$ and $\mathrm{D}$, and group D mostly consisted of fibrous scar tissue formation.

\section{Electrophysiologic-Anatomic Mapping for Electrical Activity}

Four animals in group B survived to and throughout the entire mapping session, whereas 1 animal died of an anesthetic complication before the mapping study. The operator was blinded as to the location of the patch; 90 to 327 (mean $209 \pm 111$ ) endocardial points were taken in 4 procedures and recreated the right ventricle chamber. All mapping sessions identified the region of patch transplantation as lower voltage. However, the patch area demonstrated both contiguous and heterogeneous voltage with the adjacent nonpatch myocardium with ranges from 0.5 to greater than $1.5 \mathrm{mV}$ (Figure 2). Areas of scar or lacking electrical voltage were not identified.

\section{Macro Inspections}

No aneurysmal changes in the implanted patches were observed in any animals. The gelatin hydrogel in group B had completely degraded and diminished. The epicardial side of the patch area in groups B and $\mathrm{U}$ showed minimal adhesions, whereas there were strong adhesions and deformity in the patch area in group D. In groups B and U, the endocardial surface of the patch was covered with wellorganized thin white layer tissue, and the thickness of remodeled tissues was almost equal to that of the normal right ventricular wall (Figure 3). On the contrary, a stiff and thick fibrous encapsulation was present in group D.

\section{Histology and Immunohistochemistry}

Histology results are shown in Figure 4. Group B patches showed infiltration of repopulated host cells through the entire layer of the patch, whereas patches in groups $\mathrm{U}$ and $\mathrm{D}$ were limited to the layers on the patch. The cells observed in group B included a wide distribution of both tropomyosin and $\alpha$-sarcomeric actinin-positive 
SIS-ECM-FGF-2 patch

(Group B)

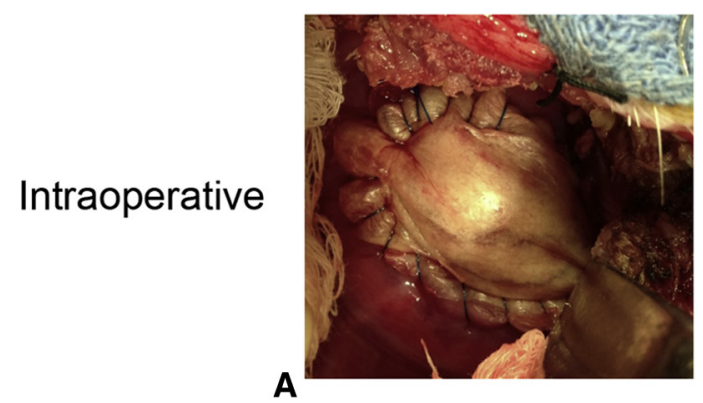

A

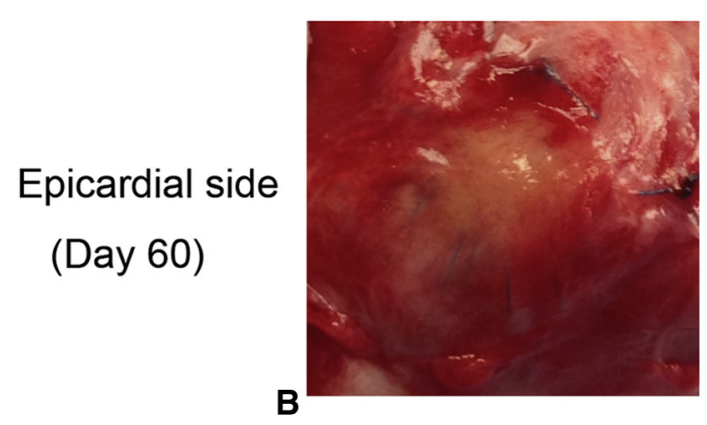

Endocardial side

(Day 60)

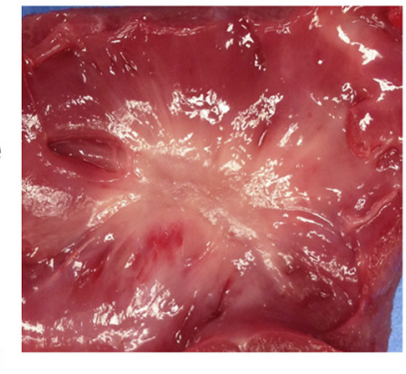

\section{Cross section}

(Day 60)

\section{D}

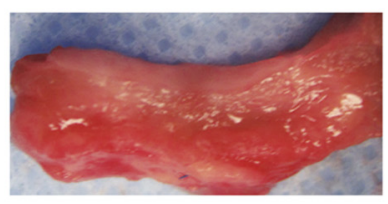

H
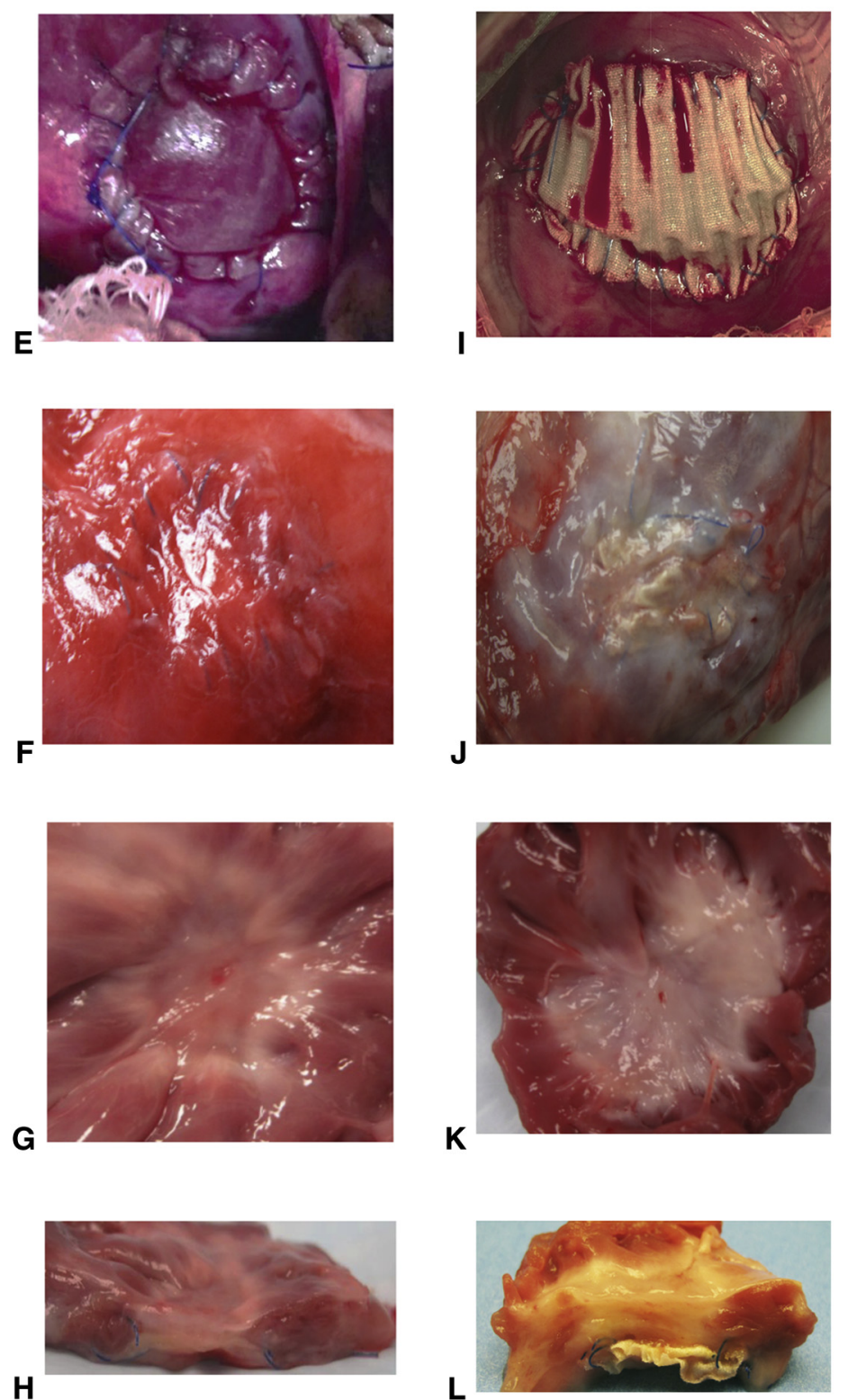

FIGURE 3. Macro inspection. Intraoperative views (A, E, I), epicardial views at 60 days (B, F, J), endocardial views at 60 days (C, G, K), and cross-section views at 60 days $(\mathrm{D}, \mathrm{H}, \mathrm{L})$ are demonstrated: A-D, SIS-ECM-FGF-2 patch. E-H, SIS-ECM patch. I-L, Dacron patch. SIS-ECM-FGF-2, Small intestine submucosa-extracellular matrix-basic fibroblast growth factor; SIS-ECM, small intestine submucosa-extracellular matrix.

cells. Tropomyosin-positive cells represent the maturing cardiomyocyte at a very early stage, and $\alpha$-sarcomeric actinin is positive in later passage of the maturing cardiomyocyte. ${ }^{18}$ The $\alpha$-sarcomeric actinin-positive cells were somewhat present in group $\mathrm{U}$, but were localized and scattered. The surface of the patches in groups B and U was covered with a well-organized monolayer of endothelial cells (vWF positive) but not in group D. The findings in group D were associated with infiltration of lymphoid cells consistent with a foreign body response with no presence of tropomyosin or $\alpha$-sarcomeric actinin-positive cells.

\section{Capillary Density}

Group B demonstrated the highest median capillary density $\left(/ \mathrm{mm}^{2}\right)$ with statistical significance over the controls, and there was also a statistically significant difference between groups $\mathrm{U}$ and $\mathrm{D}$ (group $\mathrm{B}=18$ [15-24], group $\mathrm{U}=13$ [11-14], group $\mathrm{D}=6$ [4-8]; group $\mathrm{B}$ vs group $\mathrm{U}$, 
SIS-ECM-FGF-2 patch

(Group B)
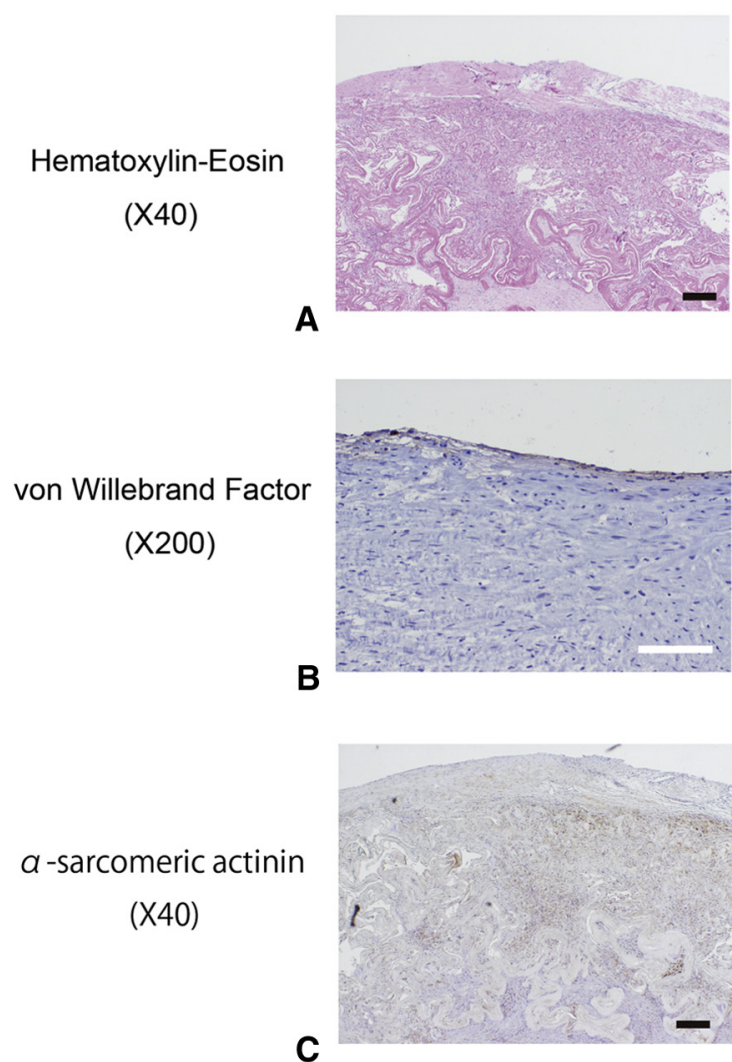

C

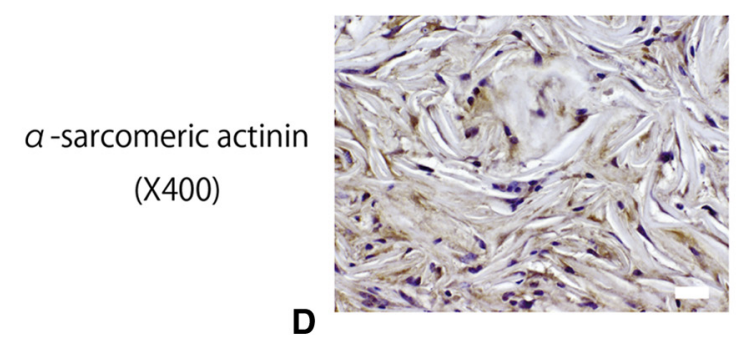

tropomyosin

(X400)

\section{SIS-ECM patch}

(Group U)
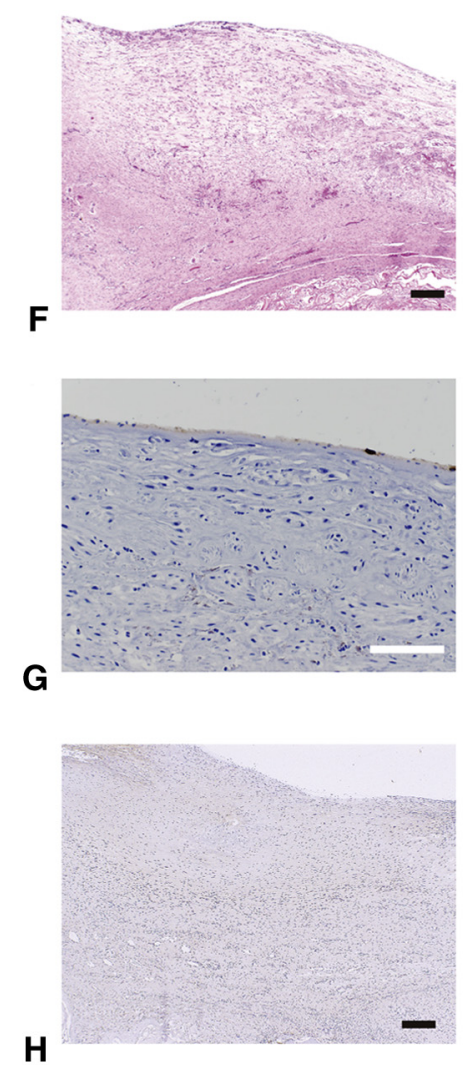

H
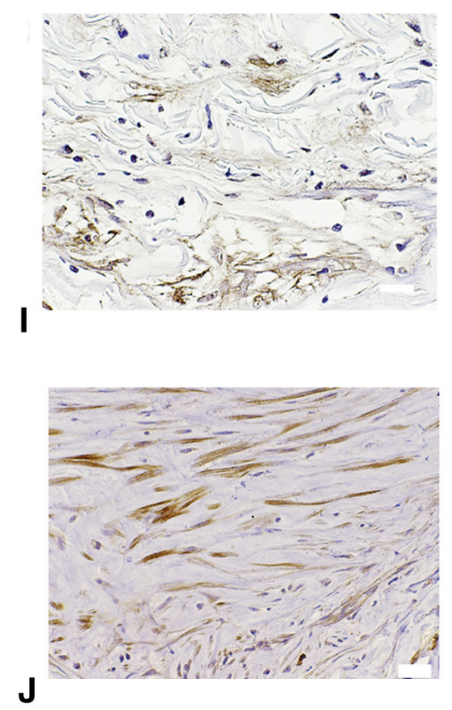

$\mathbf{N}$

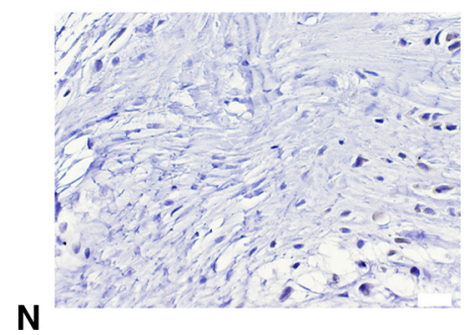

K

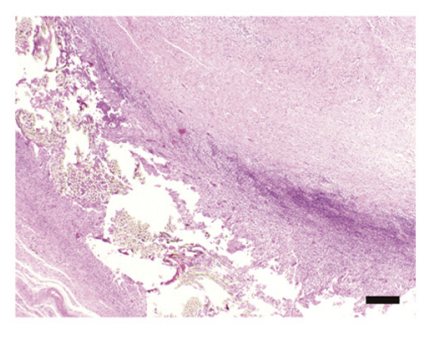

$\mathbf{L}$

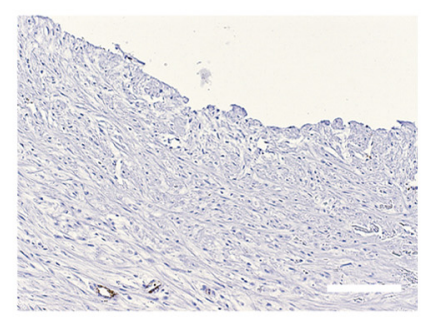

M
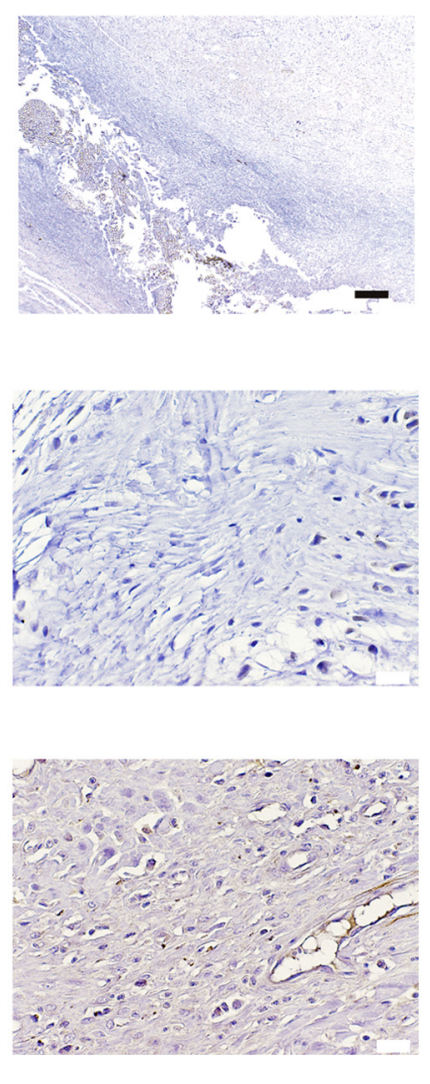

FIGURE 4. Histology and immunohistochemistry. SIS-ECM-FGF-2 (A-E): Homogenous distribution of repopulated host cells infiltrating through the entire layer of the patch is seen, including $\alpha$-sarcomeric actinin and tropomyosin-positive cells, suggesting the presence of maturing cardiomyocytes. The endocardial surface is covered with a monolayer of endothelial cells (vWF-positive cells). SIS-ECM (F-J): Well-organized cells including monolayer of endothelial cells on the endocardial surface and layers of scattered $\alpha$-sarcomeric actinin and tropomyosin-positive cells were observed. The repopulated cells were predominantly developed on the SIS-ECM sheet rather than infiltrating in the SIS-ECM layers. Dacron (K-O): Significant infiltration of lymphoid cells is observed, consistent with a foreign body response with no presence of vWF, $\alpha$-sarcomeric actinin, or tropomyosin-positive cells. Black bar $=200 \mu \mathrm{m}$. White bar $=100 \mu \mathrm{m}$. SIS-ECM-FGF-2, Small intestine submucosa-extracellular matrix-basic fibroblast growth factor; SIS-ECM, small intestine submucosa-extracellular matrix. 


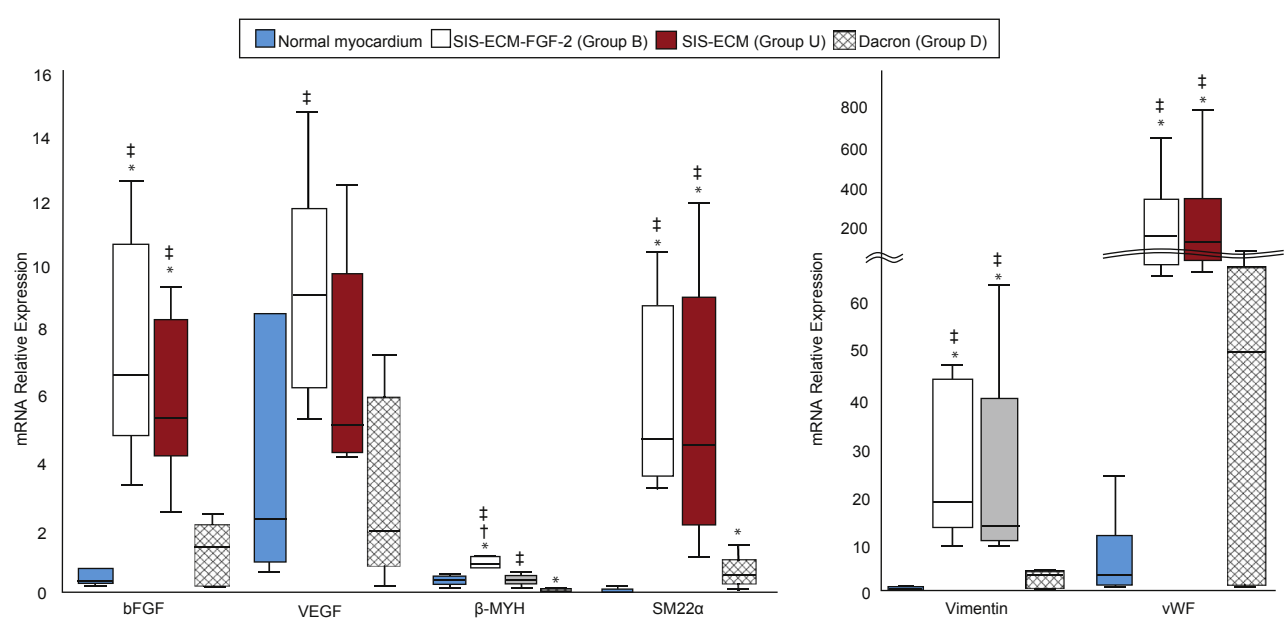

FIGURE 5. Real-time polymerase chain reaction. mRNA expression was normalized by the expression of a housekeeping gene (GAPDH). Comparison with normal myocardium: $* P<.05$. Comparison with SIS-ECM (U): $\dagger P<.05$. Comparison with Dacron (D): $\ddagger P<.05$. SIS-ECM-FGF-2, Small intestine submucosa-extracellular matrix-basic fibroblast growth factor; SIS-ECM, small intestine submucosa-extracellular matrix; VEGF, vascular endothelial growth factor; $b F G F$, basic fibroblast growth factor; $\beta$ - $M Y H, \beta$-myosin heavy chain; $S M 22 \alpha$, smooth muscle $22 \alpha$; $\nu W F$, von Willebrand factor.

$P<.001$; group $\mathrm{B}$ vs group $\mathrm{D}, P=.008$; group $\mathrm{U}$ vs group $\mathrm{D}, P=.021$ ) (Figure E1). The capillary structures were predominantly distributed in the layers close to the patch materials in all 3 groups, with the exception that the capillary-rich layer in group B was the thickest and extending toward the endocardial side.

\section{Quantitative Reverse Transcription-Polymerase Chain Reaction}

The results are summarized in Table E2 and Figure 5. In groups $\mathrm{B}$ and $\mathrm{U}$, the early mesenchymal markers (ie, smooth muscle $22 \alpha$, vimentin) were expressed significantly more compared with group D and the normal myocardium. Expression of vWF was similar in groups $\mathrm{B}$ and $\mathrm{U}$ and was statistically different from the normal myocardium. The expressions of $\beta$-myosin heavy chain, a marker for the early developmental stage of cardiomyocyte, were significantly positive in groups $\mathrm{B}$ and $\mathrm{U}$, whereas they were not detected in group D. Both vascular endothelial growth factor and FGF-2 were expressed significantly more in groups $\mathrm{B}$ and $\mathrm{U}$ than in group $\mathrm{D}$. Overall, groups $B$ and $U$ were similar in composition of those markers, but there was a tendency that each marker in group B was greater than one in group $\mathrm{U}$, although there was no statistical difference.

\section{DISCUSSION}

The present study demonstrated that controlled release of FGF-2 as an adjunct to the SIS-ECM was associated with increased proliferation of host cells with early signs of positive constructive myocardial remodeling. Histology showed that the endocardial side of the SIS-ECM with FGF-2 was homogenously covered with a monolayer of endothelial cells, and constructive repopulation of host cells was present throughout the whole layer. In addition, tropomyosin and $\alpha$-sarcomeric actinin-positive cells, suggesting maturing cardiomyocytes, were observed between the layers of SIS-ECM along with well-developed angiogenesis/vasculogenesis. These histologic findings were consistent with reverse transcription-polymerase chain reaction results. The morphologic and histologic observations and reverse transcription-polymerase chain reaction analyses imply that the reparative pathways for untreated SIS-ECM patches and patches with FGF-2 were similar, but that the rate of regeneration process was faster in the FGF-2-treated SIS-ECM. This would also support the long-standing presence of FGF-2 in the patch area by the controlled-release function contributed to expediting the remodeling process. Furthermore, the regional strain and contrast-enhanced perfusion, as measured by CMR, suggest the early restoration of contractility and tissue perfusion in the SIS-ECM patch with FGF-2 when compared with the control patches; the positive decrease in ECV also supports the concept that fibrous tissue was actively replaced with functional host cells. Electromechanical mapping showed the presence of electrical activity on the SIS-ECM patch with FGF-2 at 60 days after implantation.

Our methodology to assess regional properties of implanted patches using CMR techniques is novel and carries a high potential to evaluate the remodeling process of tissue-engineered material in vivo. CMR has been used to evaluate tissue-engineered cardiac materials, but these studies were limited to assessment of the global heart function or tissue perfusion. ${ }^{19}$ We report a comprehensive CMR-based assessment that includes (1) SENC for quantification of regional myocardial contractility ${ }^{12}$; (2)perfusion imaging for the assessment of regional myocardial blood flow $^{13}$; and (3) T1 mapping using MOLLI to quantify the 
extent of fibrosis. ${ }^{14}$ Together these techniques could provide valuable insight into the underlying reconstructive remodeling process of myocardial tissue. Such a comprehensive assessment of the underlying structure of the myocardium/ patch is more challenging using other modalities, such as echocardiography. ${ }^{20}$

The ability for transplanted tissue patches to regenerate electrical voltage that is contiguous to the adjacent tissue is significant. Mechanical function of the muscle is directly tied to the electrical depolarization and parallel activation of the tissue leading to contraction..$^{21,22}$ Tissue remodeling is an important function in viable tissue and especially cardiac muscle. It has been noted to continue over time with good perfusion and adequate electrical voltage. ${ }^{21}$ Our results of positive electrical conductivity in the FGF-2-enhanced ECM patch and increased contractility demonstrated by CMR may suggest that viable tissue constructively remodeled enough to begin contracting consequent to linked electrical synapses. However, although this is a proof-of-concept study, there was no control group to compare in the electrical mapping study. Therefore, it is not intended to be conclusive on this result but just to show the objective data for reference. Further study is warranted to confirm the electrical activity in the patch area and fully understand the relationship between the regeneration of electrical conductivity and the mapping study.

FGF-2 is the first reported angiogenic factor, ${ }^{23}$ and its intracoronary ${ }^{24,25}$ and intramyocardial ${ }^{26}$ delivery has demonstrated efficacy in treating damaged myocardium in animal models. In addition to facilitating angiogenesis, FGF-2 possesses favorable effects on in situ site-specific tissue regeneration and remodeling: mobilization of endogenous cell populations, induction of cell differentiation, and prevention of maladaptive fibrosis. ${ }^{8,9}$ FGF-2 has been commercially available for clinical use in Japan since 2001, and its long-term safety and efficacy in human have been proven. ${ }^{27,28}$ We chose FGF-2 to use in the present study because of the favorable effects and safety.

Gelatin is a natural polymer derived from collagen commonly used for pharmaceutical and medical applications because of its biodegradability and biocompatibility. Acidic gelatin hydrogel binds FGF-2 by reciprocal electric affinity. ${ }^{11,29}$ FGF-2 is sustained in the gelatin hydrogel while retaining its biological activity. ${ }^{11}$ FGF-2 is released as the enzymatic degradation of the gelatin hydrogel in vivo, resulting in the controlled release. The use of FGF-2 with the gelatin hydrogel has been reported in regenerative medicine, including cardiac tissue repair, with superior results compared with the direct application of FGF-2 without a sustained delivery system. ${ }^{26,30}$ The gelatin hydrogel sheet used in this study was designed for sustained FGF-2 release for more than 28 days as reported previously by Tabata and Ikada ${ }^{11}$ and Kitamura and colleagues. ${ }^{28}$ Briefly, the water content of the hydrogel determines its degradation rate: In vivo implantation data demonstrate that hydrogels with a water content of $98.8 \%$ dissolve in 10 days, whereas hydrogels with water content of $96.9 \%$ degrade at 35 days. Unlike in previous reports of soaking the ECM scaffold in solution with growth factors ${ }^{9,10}$ this is the solid method to deliver the growth factor without being washed away by the bloodstream.

Previous works related with ECM materials to repair damaged myocardium can be classified in 2 categories: cell-seeded and non-cell-seeded. To date, cell-seeded patches have not met expectations and have several issues, such as unfavorable inflammatory reactions, ${ }^{31}$ low seeded cell survival ( $36.5 \%$ at 4 weeks), and electrical uncoupling of the seeded cells to the host cells. ${ }^{32}$ Non-cell-seeded ECM patches have demonstrated their efficacy in preventing maladaptive remodeling of the subacute infarcted myocardium without inflammatory responses. ${ }^{9,33}$ However, host cell repopulation within these biodegradable patches has been "too slow" or suboptimal. Thus, in addition to the advantages of the non-cell-seeded ECM patch, we believe our concept of incorporating the FGF-2 controlled-release technique into SIS-ECM is a promising technique to expedite the remodeling process. The results in this study demonstrated that the SIS-ECM with controlled release of FGF-2 was associated with in situ constructive remodeling with regeneration and repopulation of cardiomyocytes. Moreover, although previous studies used custom-designed ECM scaffolds, ${ }^{10,31-33}$ the SIS-ECM used in the present study is commercially available and has proved its safety in clinical use as an "off-the-shelf" product offering a variety of applications in many organs, including the heart. ${ }^{5,6}$

Future clinical applications of our material would include use in surgical ventricular restoration (SVR) procedures. Although SVR is an important treatment alternative to heart transplantation and mechanical circulatory support, it suffers from insufficient outcomes likely because of the use of large inert patch materials. ${ }^{34}$ Our cardiac patch could contribute to regional functional recovery of the heart by in situ myocardial regeneration, and subsequently improve clinical outcomes after SVR. To allow a variety of clinical applications, our cardiac patch was designed to tolerate a high-pressure environment in the left-sided heart, including substituting damaged myocardial tissues in full thickness when necessary. Although SIS-ECM, which is the base material of our cardiac patch, has been clinically used in left ventricular repair and preliminarily proved to tolerate in such an environment, ${ }^{35}$ further studies to test the durability of our material in a left ventricular model are warranted.

\section{Study Limitations}

First, this study evaluated only a single time point at 60 days after the cardiac implantation surgery. It is known that naturally occurring SIS-ECM scaffolds commence degradation 60 to 90 days postimplantation. ${ }^{2}$ Although 
expedited reconstructive remodeling in SIS-ECM with the FGF-2 patch was observed compared with untreated SISECM, further assessment over a longer term is warranted. Second, a right ventricular model was used in this proofof-concept study because it was cost-effective and to decrease mortality and morbidity for the animals. It is important to test our patch in a left ventricular infarcted model, which eventually would be our clinical target population. Third, although the in vivo kinetics of FGF-2 have been well documented in previous studies, ${ }^{8,26,29,30}$ they were not investigated in the present proof-of-concept study. We are planning to conduct related analyses in a future study (eg, tissue concentration of FGF-2, radioisotope tagging study).

\section{CONCLUSIONS}

SIS-ECM with controlled release of FGF-2 demonstrated expedited site-specific constructive host cell repopulation and significantly increased regional contractility and electrical activity. This material might be a substitute for the prosthetic materials used in surgical heart repair and provide functional recovery of the heart. Further studies in long-term and postinfarct left ventricular models are warranted.

\section{Conflict of Interest Statement}

ARP receives research support from Philips Healthcare North America Corp (Andover, Mass). All other authors have nothing to disclose with regard to commercial support.

\section{References}

1. Roger VL, Weston SA, Redfield MM, Hellermann-Homan JP, Killian J, Yawn BP, et al. Trends in heart failure incidence and survival in a community-based population. JAMA. 2004;292:344-50.

2. Badylak S, Kokini K, Tullius B, Simmons-Byrd A, Morff R. Morphologic study of small intestinal submucosa as a body wall repair device. J Surg Res. 2002;103: 190-202.

3. Brountzos E, Pavcnik D, Timmermans HA, Corless C, Uchida BT, Nihsen ES, et al. Remodeling of suspended small intestinal submucosa venous valve: an experimental study in sheep to assess the host cells' origin. J Vasc Inerv Radiol. 2003; 14:349-56.

4. Stelly M, Stelly TC. Histology of CorMatrix bioscaffold 5 years after pericardial closure. Ann Thorac Surg. 2013;96:e127-9.

5. Sundermann SH, Rodriguez Cetina Biefer H, Emmert MY, Falk V. Use of extracellular matrix materials in patients with endocarditis. Thorac Cardiovasc Surg. 2014:62:76-9.

6. Zaidi AH, Nathan M, Emani S, Baird C, del Nido PJ, Gauvreau K, et al. Preliminary experience with porcine intestinal submucosa (CorMatrix) for valve reconstruction in congenital heart disease: Histologic evaluation of explanted valves. J Thorac Cardiovasc Surg. 2014;148:2216-25.

7. Toeg HD, Tiwari-Pandey R, Seymour R, Ahmadi A, Crowe S, Vulesevic B, et al. Injectable small intestine submucosal extracellular matrix in an acute myocardial infarction model. Ann Thorac Surg. 2013;96:1686-94.

8. Tabata Y. Tissue regeneration based on growth factor release. Tissue Eng. 2003; 9(Suppl 1):S5-15.

9. Mewhort HE, Turnbull JD, Meijndert HC, Ngu JM, Fedak PW. Epicardial infarct repair with basic fibroblast growth factor-enhanced CorMatrix-ECM biomaterial attenuates postischemic cardiac remodeling. J Thorac Cardiovasc Surg. 2014; 147:1650-9.
10. Ota T, Gilbert TW, Schwartzman D, McTiernan CF, Kitajima T, Ito Y, et al. A fusion protein of hepatocyte growth factor enhances reconstruction of myocardium in a cardiac patch derived from porcine urinary bladder matrix J Thorac Cardiovasc Surg. 2008;136:1309-17.

11. Tabata Y, Ikada Y. Vascularization effect of basic fibroblast growth factor released from gelatin hydrogels with different biodegradabilities. Biomaterials. 1999;20:2169-75.

12. Osman NF, Sampath S, Atalar E, Prince JL. Imaging longitudinal cardiac strain on short-axis images using strain-encoded MRI. Magn Reson Med. 2001;46: 324-34.

13. Wilke NM, Jerosch-Herold M, Zenovich A, Stillman AE. Magnetic resonance first-pass myocardial perfusion imaging: clinical validation and future applications. J Magn Reson Imaging. 1999;10:676-85.

14. Messroghli DR, Radjenovic A, Kozerke S, Higgins DM, Sivananthan MU, Ridgway JP. Modified Look-Locker inversion recovery (MOLLI) for high-resolution T1 mapping of the heart. Magn Reson Med. 2004;52:141-6.

15. Hamdan A, Thouet T, Kelle S, Paetsch I, Gebker R, Wellnhofer E, et al. Regional righ ventricular function and timing of contraction in healthy volunteers evaluated by strain-encoded MRI. J Magn Reson Imaging. 2008;28:1379-85.

16. Schuleri KH, Amado LC, Boyle AJ, Centola M, Saliaris AP, Gutman MR, et al Early improvement in cardiac tissue perfusion due to mesenchymal stem cells. Am J Physiol Heart Circ Physiol. 2008;294:H2002-11.

17. Kellman P, Arai AE, Xue H. T1 and extracellular volume mapping in the heart: estimation of error maps and the influence of noise on precision. J Cardiovasc Magn Reson. 2013;15:56.

18. Shim WS, Jiang S, Wong P, Tan J, Chua YL, Tan YS, et al. Ex vivo differentiation of human adult bone marrow stem cells into cardiomyocyte-like cells. Biochem Biophys Res Commun. 2004:324:481-8.

19. Riegler J, Gillich A, Shen Q, Gold JD, Wu JC. Cardiac tissue slice transplantation as a model to assess tissue-engineered graft thickness, survival, and function. Circulation. 2014;130:S77-86.

20. Sanz J, Conroy J, Narula J. Imaging of the right ventricle. Cardiol Clin. 2012;30: 189-203.

21. Brinks H, Giraud MN, Segiser A, Ferrié C, Longnus S, Ullrich ND, et al Dynamic patterns of ventricular remodeling and apoptosis in hearts unloaded by heterotopic transplantation. J Heart Lung Transplant. 2014;33:203-10.

22. Ota T, Gilbert TW, Badylak SF, Schwartzman D, Zenati MA. Electromechanical characterization of a tissue-engineered myocardial patch derived from extracellular matrix. J Thorac Cardiovasc Surg. 2007;133:979-85.

23. Shing Y, Folkman J, Sullivan R, Butterfield C, Murray J, Klagsbrun M. Heparin affinity: purification of a tumor-derived capillary endothelial cell growth factor Science. 1984;223:1296-9.

24. Lazarous DF, Shou M, Stiber JA, Dadhania DM, Thirumurti V, Hodge E, et al. Pharmacodynamics of basic fibroblast growth factor: route of administration determines myocardial and systemic distribution. Cardiovasc Res. 1997;36: $78-85$.

25. Fearon WF, Ikeno F, Bailey LR, Hiatt BL, Herity NA, Carter AJ, et al. Evaluation of high-pressure retrograde coronary venous delivery of FGF-2 protein. Catheter Cardiovasc Interv. 2004;61:422-8.

26. Sakakibara Y, Tambara K, Sakaguchi G, Lu F, Yamamoto M, Nishimura K, et al Toward surgical angiogenesis using slow-released basic fibroblast growth factor. Eur J Cardiothorac Surg. 2003;24:105-11.

27. Hayashida K, Akita S. The quality of pediatric second-degree burn scars following the application of basic fibroblast growth factor. Ostomy Wound Manage. 2012;58:32-6.

28. Kitamura M, Akamatsu M, Machigashira M, Hara Y, Sakagami R Hirofuji T, et al. FGF-2 stimulates periodontal regeneration. J Dent Res. 2011;90:35-40.

29. Ozeki M, Tabata Y. In vivo degradability of hydrogels prepared from different gelatins by various cross-linking methods. J Biomater Sci Polym Ed. 2005;16: 549-61.

30. Takehara N, Tsutsumi Y, Tateishi K, Ogata T, Tanaka H, Ueyama T, et al Controlled delivery of basic fibroblast growth factor promotes human cardiosphere-derived cell engraftment to enhance cardiac repair for chronic myocardial infarction. J Am Coll Cardiol. 2008;52:1858-65.

31. Leor J, Aboulafia-Etzion S, Dar A, Shapiro L, Barbash IM, Battler A, et al Bioengineered cardiac grafts: A new approach to repair the infarcted myocardium? Circulation. 2000;102(suppl III):III-56-61.

32. Wendel JS, Ye L, Zhang P, Tranquillo RT, Zhang JJ. Functional consequences of a tissue-engineered myocardial patch for cardiac repair in a rat infarct model. Tissue Eng Part A. 2014;20:1325-35. 
33. Fujimoto KL, Tobita K, Merryman WD, Guan J, Momoi N, Stolz DB, et al. An elastic, biodegradable cardiac patch induces contractile smooth muscle and improves cardiac remodeling and function in subacute myocardial infarction. $J$ Am Coll Cardiol. 2007;49:2292-300.

34. Suma H, Anyanwu AC. Current status of surgical ventricular restoration for ischemic cardiomyopathy. Semin Thorac Cardiovasc Surg. 2012;24: 294-301.
35. Yanagawa B, Rao V, Yau TM, Cusimano RJ. Initial experience with intraventricular repair using CorMatrix extracellular matrix. Innovations (Phila). 2013;8:348-52.

Key Words: cardiovascular magnetic resonance imaging, drug delivery system, growth factor, myocardial repair, tissue engineering

\title{
EDITORIAL COMMENTARY
}

\section{The clinical application potential of extracellular matrix in cardiac tissue engineering}

\author{
Kay Maeda, MD, PhD, and Marc Ruel, MD, MPH, FRCSC
}

\footnotetext{
From the Division of Cardiac Surgery, University of Ottawa Heart Institute, Ottawa, Ontario, Canada. Disclosures: Authors have nothing to disclose with regard to commercial support.

Received for publication Aug 2, 2015; accepted for publication Aug 3, 2015; available ahead of print Aug 28, 2015.

Address for reprints: Marc Ruel, MD, MPH, FRCSC, Division of Cardiac Surgery, University of Ottawa Heart Institute, 40 Ruskin St, Suite 3402, Ottawa, Ontario, Canada (E-mail: mruel@ ottawaheart.ca).

J Thorac Cardiovasc Surg 2015;150:1290-1

$0022-5223 / \$ 36.00$

Copyright $\odot 2015$ by The American Association for Thoracic Surgery

http://dx.doi.org/10.1016/j.jtcvs.2015.08.007
}

An extracellular matrix (ECM) scaffold derived from porcine small intestinal submucosa (SIS) is currently used clinically for various disorders and constitutes one of the most extensively characterized decellularized ECM materials. A SIS-ECM scaffold can provide an ideal extracellular environment for cells and serve as a possible substitute for damaged tissue because of its high content of natural ECM components, such as collagens, fibronectin, elastin, glycosaminoglycans, and various growth factors. ${ }^{1}$ In cardiovascular tissue engineering, the SIS-ECM patch has been investigated experimentally and clinically as an on-lay patch or an interposition graft to promote tissue reconstruction. ${ }^{2-6}$ Polytetrafluoroethylene and polyester (Dacron) grafts conventionally have been used successfully for vascular and intraventricular repair (eg, surgical ventricular restoration). However, major concerns related to these synthetic grafts include reactive inflammation, calcification, infections, adhesions, and local stiffness over a long period. An ECM-based scaffold could carry a lower risk of these complications because of its nontoxic, nonimmunogenic, biodegradable, and contractile properties. Furthermore, SIS-ECM has a predominant potential for cellular repopulation and ingrowth of the host cells, neovascularization, and ultimately, restoration of regional tissue functionality.

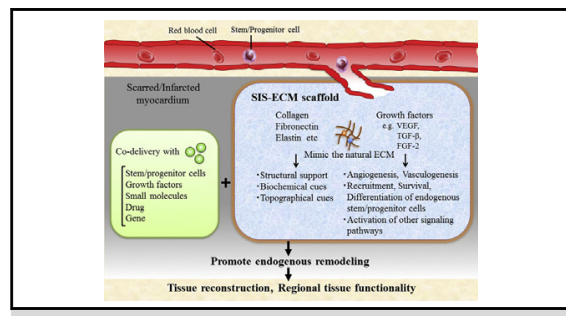

The potential of SIS-ECM scaffolds for cardiac regeneration.

Central Message

A SIS-ECM patch with sustained release of FGF-2 has potential as a plausible approach to regenerate damaged myocardium.

See Article page 1280

See Editorial page 1035.

The research reported in this issue of the Journal by Tanaka and colleagues ${ }^{7}$ shows that a SIS-ECM patch with sustained release of basic fibroblast growth factor-2 (FGF-2) improved regional contractility and tissue perfusion in a porcine right ventriculotomy model compared with groups treated with a SIS-ECM patch alone or a Dacron patch. The authors assessed regional functionality using cardiovascular magnetic resonance and electrophysiologic-anatomic mapping. These techniques could provide comprehensive assessment of in situ myocardial reconstruction, such as electrical conductivity. Ramos and colleagues ${ }^{3}$ and Yanagawa and colleagues ${ }^{4}$ have demonstrated the effects of a SIS-ECM patch for porcine left ventricular and human intraventricular repair, although 


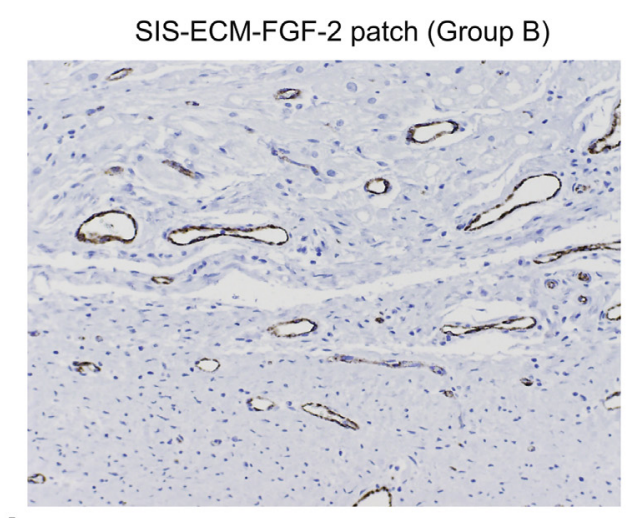

A

von Willebrand factor (X200)
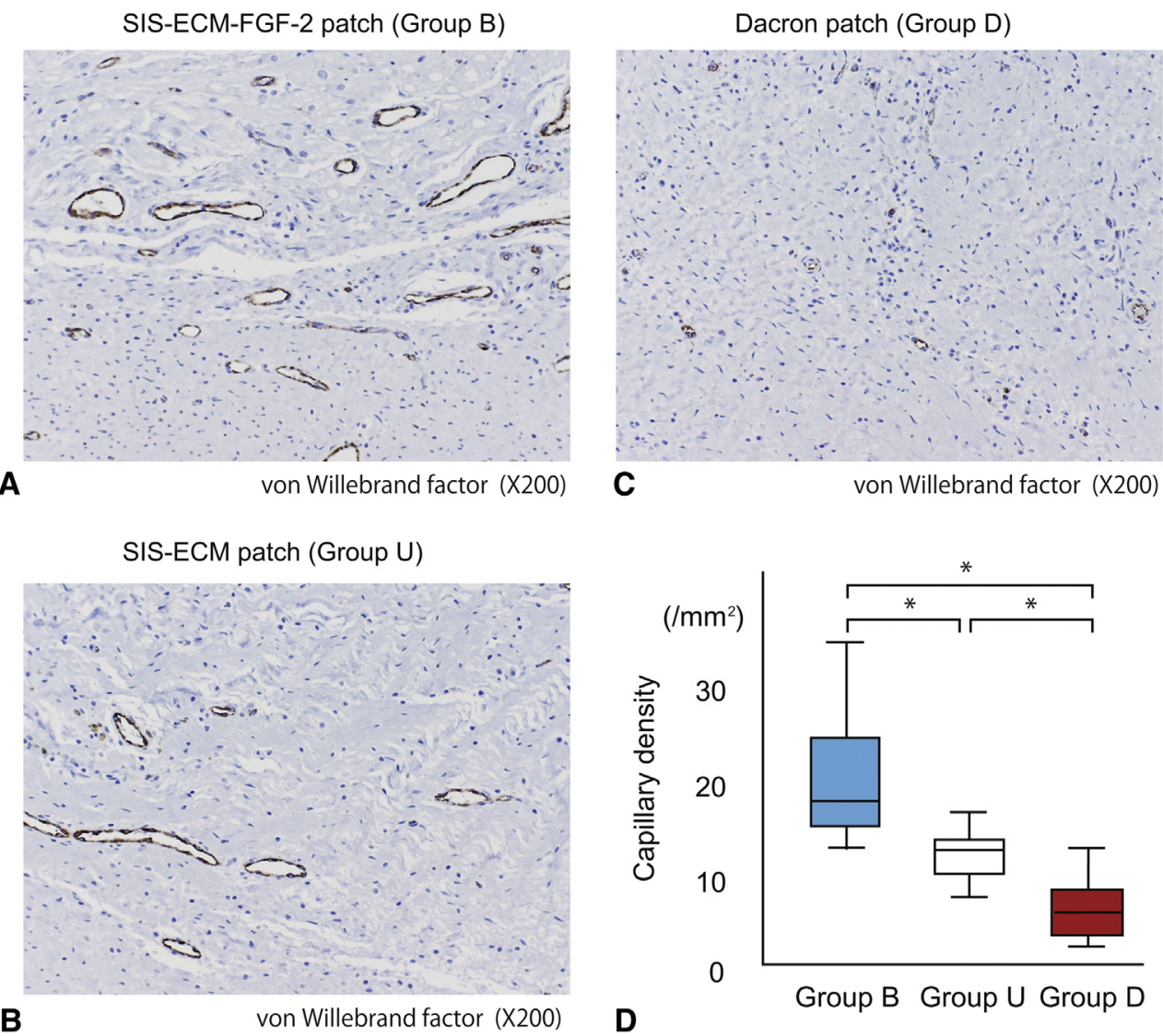

FIGURE E1. Capillary density. A-C, Representative vWF immunohistochemical staining in each patch. D, Capillary density $* P<.05$. SIS-ECM, Small intestine submucosa-extracellular matrix; $S I S-E C M-F G F-2$, small intestine submucosa-extracellular matrix-basic fibroblast growth factor. 
TABLE E1. Primers and probes for quantitative reverse transcription polymerase chain reaction

\begin{tabular}{|c|c|c|}
\hline Gene & $\begin{array}{c}\text { Primer and } \\
\text { Probe }\end{array}$ & Sequence $\left(5^{\prime}-3^{\prime}\right)$ \\
\hline \multirow[t]{3}{*}{ GAPDH } & Primer forward & CTGCACCACCAACTGCTTAGC \\
\hline & Primer reverse & GCCATGCCAGTGAGCTTCC \\
\hline & Probe & CCTGGCCAAGGTCATCCATGACCACTTC \\
\hline \multirow[t]{3}{*}{$\operatorname{SM} 22 \alpha$} & Primer forward & GCTCCATTTGCTTGAAGACCAT \\
\hline & Primer reverse & GTAATGCAGTGTGGCCCTGA \\
\hline & Probe & CTCAAAATCACGCCGTTCTTCAGCCA \\
\hline \multirow[t]{3}{*}{ Vimentin } & Primer forward & AGGTGGCAATCTCAATGTCGA \\
\hline & Primer reverse & AAATGAGTACCGGAGACAGGTGC \\
\hline & Probe & CTCTTCCATTTCCCGCATCTGGCGTT \\
\hline \multirow[t]{3}{*}{$\beta$-MYH } & Primer forward & CTGAAGGACACCCAGATCCA \\
\hline & Primer reverse & GTTGATGAGGCTGGTCTGG \\
\hline & Probe & ACGCGGTCCGTGCCAATGATGACC \\
\hline \multirow[t]{3}{*}{ vWF } & Primer forward & ATGGAGTACACGGCTTTGCTG \\
\hline & Primer reverse & CAGGCACATGCTGTGACACAT \\
\hline & Probe & ATGAATGTCCACCTCCTCTTCAGACCGG \\
\hline \multirow[t]{3}{*}{ FGF-2 } & Primer forward & TGTGTGCAAACCGTTATCTTGCTA \\
\hline & Primer reverse & CAGTGCCACATACCAACTGGAGTA \\
\hline & Probe & CTACAATACTTACCGGTCGAGG \\
\hline \multirow[t]{3}{*}{ VEGF } & Primer forward & GACGTCTACCAGCGCAGCTACT \\
\hline & Primer reverse & TTTGATCCGCATAATCTGCATG \\
\hline & Probe & TTCCAGGAGTACCCCGATGAGATCGA \\
\hline
\end{tabular}

TABLE E2. Results of quantitative real-time reverse transcription-polymerase chain reaction

\begin{tabular}{lcccc}
\hline & Normal myocardium & SIS-ECM-FGF-2 (B) & SIS-ECM (U) & Dacron (D) \\
\hline SM22 $\alpha$ & $0.10(0.04-0.17)$ & $4.48(3.63-7.91)^{*} \ddagger$ & $4.23(2.36-8.35)^{*}, \ddagger$ & $0.88(0.69-1.33)^{*}$ \\
Vimentin & $0.3(0.1-1.3)$ & $19.4(13.4-43.8)^{*} \ddagger$ & $13.9(10.6-41.4)^{*}, \ddagger$ & $5.1(0.5-6.1)$ \\
$\beta$-MYH & $0.41(0.32-0.53)$ & $1.24(1.10-1.49)^{*}, \dagger, \ddagger$ & $0.52(0.39-0.72)_{\ddagger}^{\ddagger}$ & $0.01(0.01-0.03)^{*}$ \\
vWF & $5.7(2.9-12.5)$ & $167.2(85.4-512.7)^{*}, \ddagger$ & $127.1(77.9-515.0)^{*}, \ddagger$ & $47.8(3.8-77.8)$ \\
FGF-2 & $0.2(0.2-0.9)$ & $6.2(4.1-10.9)^{*}, \ddagger$ & $5.0(3.2-8.2)^{*}, \ddagger$ & $1.5(0.1-2.7)$ \\
VEGF & $2.6(1.5-23.3)$ & $8.5(5.9-11.9) \ddagger$ & $4.2(3.2-13.0)$ & $1.7(0.8-5.2)$ \\
\hline
\end{tabular}

Data are presented as median (interquartile range). Expressed with the mRNA level/GAPDH. $F G F-2$, Basic fibroblast growth factor; $\beta$-MYH, beta-myosin heavy chain; SIS-ECM, small intestine submucosa-extracellular matrix; $S M 22 \alpha$, smooth cell $22 \alpha$; VEGF, vascular endothelial growth factor; $v W F$, von Willebrand factor. $P<.05 *$ versus normal myocardium. †versus SIS-ECM (U). ‡versus Dacron (D). 